\title{
CORRESPONDENCE
}

(To the Editors of the Journal of the Institute of Actuaries)

Dear Sirs,

\section{Mortality of Assured Lives in South Africa}

In F.I.A. 87 a report is given of the mortality investigations by the Actuarial Society of South Africa and on page $38 \mathrm{r}$ it is suggested that one of the main reasons for the relatively high mortality, particularly at the younger ages, may well be the high accident rate in the Union.

It is interesting to compare the graduated mortality rates shown on pages 379 and 380 of $\mathcal{Y}$.I.A. 87 with those derived from the investigations of the Australasian Actuarial Society into the experience of the principal Australian companies from $1953-58$. Somewhat similar physical conditions exist in both countries and this leads to a comparatively high rate of death from accidents. The figures also show the typical 'bump' about age zo. The comparison is for 100,000 $q_{x}$.

$\begin{array}{ccc}\text { Age } & \begin{array}{c}\text { European Lives } \\ \text { South Africa }\end{array} & \text { Australia } \\ 20 & 203 & \text { I33 } \\ 30 & 131 & 105 \\ 40 & 294 & 173 \\ 50 & 788 & 527 \\ 60 & 1944 & 1518\end{array}$

The experiences relate to much the same period of time and, in view of the substantial discrepancies, it would seem necessary to look further afield than the accident death rate to account for the heavier mortality in South Africa.

Yours sincerely, C. D. SHARP

Noble Lozndes House, Lowndes Street, London, S.W. I $23 \mathfrak{F u l y} \mathrm{I} 962$ 